\title{
Brasil na Contramão do Mundo: Mudanças no Padrão de Exportações entre 2016-2020*
}

\author{
Moving Against the World Trend: Changes in the Composition of Exports \\ between 2016-2020
}

João Prates Romero ${ }^{\dagger}$

Danielle Evelyn de Carvalho ${ }^{\ddagger}$

Arthur Ribeiro Queiroz $\$$

\author{
Ciro Eustáquio de Moura Lopes*
}

\begin{abstract}
Resumo
Ao contrário da Europa e dos Estados Unidos, o atual governo do Brasil segue uma estratégia de crescimento focada em setores primários e baseados em recursos naturais, que estão associados a maior intensidade de emissões de gases de efeito estufa e maior degradação ambiental, em detrimento de setores de maior intensidade tecnológica, que geram mais crescimento com menores impactos ambientais. A diversificação brasileira caiu de 196 indústrias competitivas em 2016 para 167 em 2020. A participação dos produtos primários na pauta exportadora aumentou de $37,2 \%$ para $44,3 \%$ no mesmo período, e a dos produtos de média e alta tecnologia caiu de $20,2 \%$ para $14,2 \%$ e de $5,2 \%$ para $3,1 \%$, respectivamente. Observou-se um aumento expressivo na quantidade de madeira bruta e ouro exportados entre 2016 e 2020. Esse crescimento gera um alerta de que uma parte dos produtos comercializados possa ser oriundo de atividades ilegais.
\end{abstract}

Palavras-chave: Estrutura produtiva; Exportações; Diversificação; Reprimarização; Degradação ambiental.

Classificação JEL: F1; O13; O44.

\footnotetext{
"Este trabalho contou com o apoio do CNPq. Os autores gostariam de agradecer a um revisor anônimo por suas considerações. Eventuais problemas remanescentes são de responsabilidade dos autores.

† Professor Adjunto do CEDEPLAR-UFMG. Contato: jpromero@cedeplar.ufmg.br

* Mestre pela Universidade Federal de Viçosa (UFV) e doutoranda no CEDEPLAR-UFMG. Contato: danielle-evelyn@hotmail.com

$\checkmark$ Graduado em economia na Universidade Federal de Minas Gerais (UFMG) e mestrando pelo CEDEPLAR-UFMG. Contato: queirozrarthur@gmail.com

** Bacharel em Ciências Econômicas pela UFMG. Contato: ciroemlopes@gmail.com
} 


\begin{abstract}
Unlike Europe and the United States, the Brazilian government adopts a growth strategy focused on primary and natural resource-based sectors, which are associated with larger intensity of greenhouse gas emissions and broader environmental degradation, instead of sectors with greater technological intensity, which generate more growth with less environmental impacts. The diversification of the Brazilian economy fell from 196 competitive industries in 2016 to 167 in 2020. The share of primary goods in total exports increased from $37.2 \%$ to $44.3 \%$ in the same period, and the share of medium and high technology products fell from $20.2 \%$ to $14.2 \%$ and from $5.2 \%$ to $3.1 \%$, respectively. We found a significant increase in the amount of raw wood and gold exported between 2016 and 2020. This growth increases the alert that a part of the products sold may come from illegal activities.
\end{abstract}

Keywords: Productive structure; Exports; Diversification; Reprimarization; Ambiental degradation.

JEL Classification: F1; O13; O44. 


\section{Introdução}

Nos últimos anos, acumularam-se evidências a respeito dos efeitos positivos do aumento do nível de complexidade econômica para o desenvolvimento econômico. Os resultados seminais de Hausmann et al. (2014) apontaram que o aumento da complexidade prevê crescimento significativo da taxa de crescimento da renda per capita no futuro. Hartmann et al. (2017) mostraram que o aumento da complexidade contribui também para reduzir a desigualdade de renda. Por fim, Mealy e Teitelboym (2020) e Romero e Gramkow (2021) apontaram que maior complexidade conduz também à redução de impactos ambientais.

O índice de complexidade econômica (ICE) mede o nível de conhecimento produtivo presente em cada economia. Economias complexas são aquelas competitivas em um número elevado de indústrias nas quais poucos países são especializados. Em outras palavras, elevada complexidade está relacionada à diversificação produtiva em setores de menor ubiquidade.

Para medir a competitividade de cada indústria em cada país, Hausmann et al. (2014) utilizam dados desagregados de comércio. Isso se deve ao fato de dados de comércio estarem disponíveis para muitos países com elevado nível de desagregação. Esses dados possibilitam o cálculo de índices de vantagens comparativas reveladas (VCR), que são usados como indicador de competitividade de cada país em cada indústria. A partir desses índices são então determinados os níveis de complexidade de cada produto e de cada economia, com base nos seus níveis de diversificação e ubiquidade. Conforme Britto et al. (2019) demonstraram, produtos de maior intensidade tecnológica apresentam maior complexidade.

Verifica-se, no entanto, que as políticas apresentadas nos últimos anos no Brasil visam um capitalismo predatório, priorizando setores primários e baseados em recursos naturais, em oposição aos setores de maior complexidade. Dentre os produtos com menor intensidade tecnológica e que tiveram um crescimento nas exportações nos últimos ano, estão a madeira bruta e o ouro. Consonante a isso, foi verificado em outros estudos um aumento do garimpo ilegal e fragilidades na 
fiscalização do desmatamento, gerando preocupação em relação à origem desse crescimento.

Para entender os movimentos da complexidade da economia brasileira, portanto, torna-se crucial monitorar os movimentos das exportações. $\bigcirc$ presente artigo analisa a evolução da composição das exportações brasileiras entre 2016-2020, com um foco no comércio internacional de madeira bruta e ouro, e as políticas adotadas no Brasil que estão contribuindo para os resultados encontrados e as implicações das mudanças observadas.

\section{Análise das Exportações Brasileiras entre 2016 e 2020}

\subsection{Mudanças na Composição das Exportações Brasileiras}

Para avaliar as mudanças na composição das exportações brasileiras foram utilizados dados do UN Comtrade, desagregados segundo a classificação SITC (revisão 3). Os dados são analisados utilizando a divisão setorial proposta por Lall (2000), que mensura a intensidade tecnológica dos produtos, que, por sua vez, é correlacionada com seu nível de complexidade. $\bigcirc$ Gráfico 1 apresenta a evolução das exportações do Brasil de acordo com essa classificação entre 2016 e 2020. ${ }^{1}$ A trajetória da composição das exportações é sintomática.

Os grupos de produtos com a maior participação da pauta de exportações, os produtos Primários e Baseados em recursos primários, também foram aqueles que apresentaram maior crescimento. Os produtos Primários aumentaram sua participação na pauta exportadora de 37,2\% em 2016 para 44,3\% em 2020, sendo que as exportações nessa categoria apresentaram um crescimento total de 40,4\% entre 2016 e 2020. Os produtos Baseados em recursos primários mantiveram a participação de cerca de 30,0\% da pauta, embora as exportações desses produtos

\footnotetext{
${ }^{1}$ Importante notar que parte da variação do valor exportado de alguns produtos foi também em função do aumento no preço das commodities. $\bigcirc$ índice de preços das commodities calculado pelo FMI, tendo 2016 como base, apresentou um aumento de 2016 a 2018 (passando de 100 para 128,2) e uma redução de 2018 a 2020 (de 128,2 para 105,9).
} 
tenham apresentado um crescimento de 27,9\% entre 2016 e 2020. A maior parte desse crescimento, porém, ocorreu entre 2016 e 2017.

Movimento contrário foi observado para produtos de média e alta tecnologia. Tais grupos protagonizaram reduções na pauta exportadora e no valor exportado nos anos considerados. Os produtos de Média tecnologia reduziram sua participação na pauta exportadora de 20,2\% em 2016 para 14,2\% em 2020, ao passo que as exportações neste setor diminuíram 16,7\% no período. Em relação aos produtos de Alta tecnologia, a participação na composição, que já era restrita, caiu de $5,2 \%$ para $3,1 \%$, sendo que a redução total nas exportações foi a mais elevada, encolhendo em 30,6\%. Ao contrário dos produtos Primários e Baseados em recursos primários, a maior parte da queda nas exportações de Média e Alta tecnologia ocorreu entre 2018-2020.

\section{Gráfico 1- Exportações brasileiras por setor (US\$ Bilhões)}

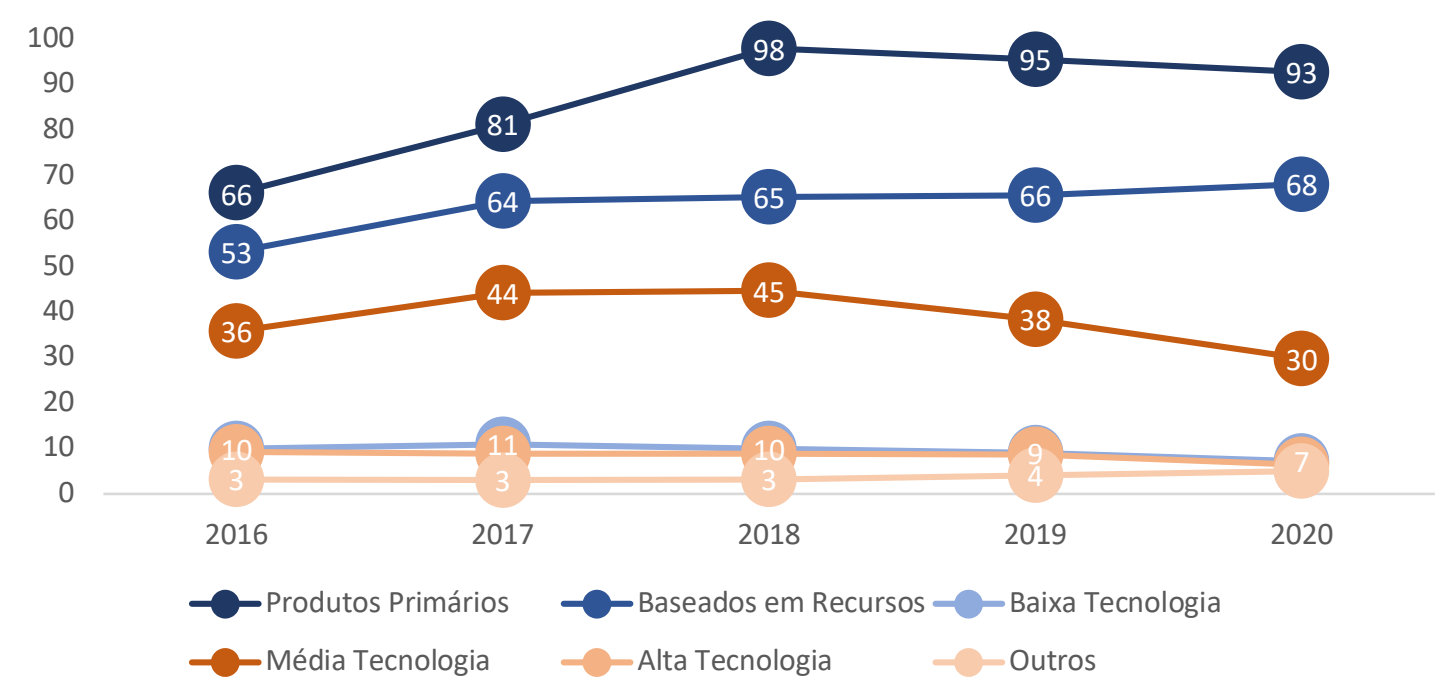

Fonte: elaboração própria a partir de dados da UN Comtrade.

\subsection{Evolução da diversificação produtiva brasileira}

G Gráfico 2 apresenta a evolução da diversificação produtiva brasileira, dividida pelos setores da classificação de Lall (2000), na classificação SITC (Revisão 
3, 4 dígitos). A diversificação é calculada como a soma das indústrias nos quais o Brasil possui vantagem comparativa revelada. ${ }^{2}$

Entre 2016 e 2020 observa-se uma queda da diversificação brasileira, que reduziu de um total de 196 indústrias competitivas em 2016 para 167 indústrias em 2020, num universo de 999 categorias de produtos. É importante notar que há queda em todas as categorias de produtos, exceto em produtos Primários, que tiveram aumento de 47 para 49 produtos competitivos. Esse resultado sugere que, ao mesmo tempo em que houve uma queda da diversificação, também ocorreu uma piora do padrão de diversificação da economia brasileira, com um aumento na competitividade em setores de baixo conteúdo tecnológico. Como resultado, segundo dados do Observatory of Economic Complexity, a complexidade brasileira caiu de 0,62 em 2016 para 0,51 em 2019, indo da posição 41 para a 49 no ranking de complexidade. Os dados para 2020 ainda não estão disponíveis.

\section{Gráfico 2- Diversificação produtiva brasileira por setor (2016-2020)}

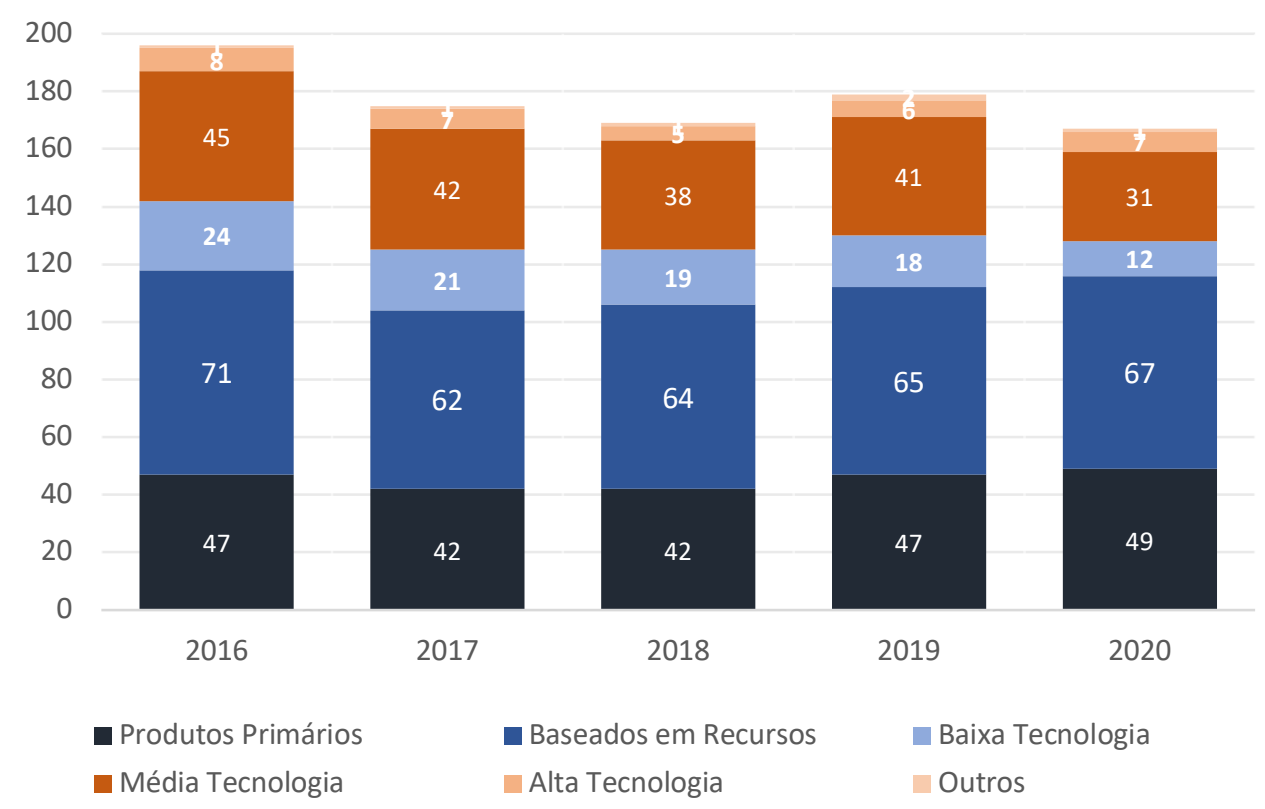

Fonte: elaboração própria a partir de dados da UN Comtrade.

\footnotetext{
${ }^{2} \mathrm{O}$ índice busca mensurar a eficiência do Brasil em se produzir determinados bens comparativamente ao mundo. O cálculo é feito da seguinte maneira: $V C R_{e p t}=\left(x_{e p t} / \sum_{p} x_{e p t}\right) /\left(\sum_{e} x_{e p t} / \sum_{e} \sum_{p} x_{e p t}\right)$, em que em que x representa as exportações do bem p pelo país e no tempo t. Se VCR $>1$, significa que o Brasil possui uma alta competitividade na produção e comercialização desse bem em relação a outras economias. E VCR $<1$ para o caso oposto.
} 
Esse padrão de especialização produtiva dificulta uma mudança estrutural rumo a produtos mais complexos. Produtos Primários apresentam um número pequeno de capacidades produtivas, e que são menos facilmente transpostas para outras atividades (Hidalgo et al., 2007). Em função disso, a especialização em primários torna mais custoso o aprendizado produtivo necessário para a produção de bens de elevada intensidade tecnológica e maior complexidade.

\subsection{Produtos primários e baseados em recursos primários}

A Tabela 1 apresenta os 20 principais produtos Primários e Baseados em recursos primários da pauta exportadora brasileira, ordenados de acordo com a respectiva participação na cesta de exportação em 2020. Esses 20 produtos sozinhos contemplam 68,7\% do valor exportado em 2020.

Os produtos Primários com maior destaque foram algodão (90,9\%), milho $(46,6 \%)$ e carne bovina (36,5\%). Os produtos Baseados em recursos primários que apresentaram maiores taxas de crescimento foram: açúcar, melaço e mel (33,5\%), minério de ferro $(27,5 \%)$ e óleos de petróleo (26,4\%).

Tabela 1- 20 Principais Produtos Baseados em Recursos Primários (PBRP) e Produtos Primários (PP)

\begin{tabular}{|c|c|c|c|c|c|c|}
\hline \multirow[b]{2}{*}{ Setor } & \multirow[b]{2}{*}{ Produto } & \multicolumn{2}{|c|}{2018} & \multicolumn{2}{|c|}{2020} & \multirow{2}{*}{$\begin{array}{l}\text { Var. \% } \\
2018- \\
2020\end{array}$} \\
\hline & & $\begin{array}{l}\text { Exp. } \\
\text { (U\$\$ } \\
\text { bi) }\end{array}$ & $\begin{array}{l}\text { Part. } \\
\text { Exp. }\end{array}$ & $\begin{array}{c}\text { Exp. } \\
(\mathrm{U} \$ \$ \mathrm{bi})\end{array}$ & $\begin{array}{l}\text { Part. } \\
\text { Exp. }\end{array}$ & \\
\hline $\mathrm{PP}$ & (222) Sementes e frutas oleaginosas & 33,3 & $14,5 \%$ & 29,0 & $13,8 \%$ & $-13,0 \%$ \\
\hline PBRP & $\begin{array}{l}\text { (281) Minério de ferro e } \\
\text { concentrados }\end{array}$ & 20,2 & $8,8 \%$ & 25,8 & $12,3 \%$ & $27,5 \%$ \\
\hline $\mathrm{PP}$ & (333) Petróleo cru, óleos de betume & 25,3 & $11,0 \%$ & 19,6 & $9,4 \%$ & $-22,325 \%$ \\
\hline PBRP & (061) Açúcar, melaço e mel & 6,6 & $2,9 \%$ & 8,9 & $4,2 \%$ & $33,5 \%$ \\
\hline $\mathrm{PP}$ & $\begin{array}{l}\text { (012) Outras carnes e sobras de } \\
\text { carnes comestíveis }\end{array}$ & 7,6 & $3,3 \%$ & 8,1 & $3,9 \%$ & $7,4 \%$ \\
\hline
\end{tabular}




\begin{tabular}{|c|c|c|c|c|c|c|}
\hline $\mathrm{PP}$ & (011) Carne bovina & 5,5 & $2,4 \%$ & 7,4 & $3,6 \%$ & $36,5 \%$ \\
\hline PP & $\begin{array}{l}\text { (081) Alimentos para animais (sem } \\
\text { cereais não moídos) }\end{array}$ & 7,1 & $3,1 \%$ & 6,5 & $3,1 \%$ & $-9,1 \%$ \\
\hline PBRP & (251) Celulose e resíduos de papel & 8,3 & $3,6 \%$ & 6,0 & $2,9 \%$ & $-27,7 \%$ \\
\hline $\mathrm{PP}$ & (044) Milho (sem incluir milho doce) & 4,0 & $1,7 \%$ & 5,9 & $2,8 \%$ & $46,6 \%$ \\
\hline $\mathrm{PP}$ & (071) Café e substitutos & 5,0 & $2,2 \%$ & 5,5 & $2,6 \%$ & $11,4 \%$ \\
\hline PBRP & $\begin{array}{l}\text { (334) Óleos de petróleo e minerais } \\
\text { betuminosos (acima de 70\% óleo) }\end{array}$ & 4,0 & $1,7 \%$ & 5,1 & $2,4 \%$ & $26,4 \%$ \\
\hline $\mathrm{PP}$ & (263) Algodão & 1,7 & $0,7 \%$ & 3,2 & $1,6 \%$ & $90,9 \%$ \\
\hline PBRP & $\begin{array}{l}\text { (285) Minério de alumínio e } \\
\text { concentrados }\end{array}$ & 2,8 & $1,2 \%$ & 2,5 & $1,2 \%$ & $-11,5 \%$ \\
\hline PBRP & $\begin{array}{l}\text { (283) Minério de cobre e } \\
\text { concentrados }\end{array}$ & 2,7 & $1,2 \%$ & 2,4 & $1,2 \%$ & $-9,2 \%$ \\
\hline PBRP & $\begin{array}{l}\text { (059) Sucos de frutas e vegetais, não } \\
\text { fermentados }\end{array}$ & 2,4 & $1,0 \%$ & 1,6 & $0,8 \%$ & $-31,8 \%$ \\
\hline PBRP & (641) Papel e papelão & 1,8 & $0,8 \%$ & 1,5 & $0,7 \%$ & $-14,7 \%$ \\
\hline $\mathrm{PP}$ & $\begin{array}{l}\text { (121) Tabaco não manufaturado } \\
\text { (248) Madeira simplesmente }\end{array}$ & 1,9 & $0,8 \%$ & 1,5 & $0,7 \%$ & $-20,1 \%$ \\
\hline PBRP & $\begin{array}{l}\text { trabalhada, e travessas ferroviárias } \\
\text { de madeira }\end{array}$ & 1,3 & $0,6 \%$ & 1,3 & $0,6 \%$ & $0,8 \%$ \\
\hline PBRP & $\begin{array}{l}\text { (017) Carnes e sobras de carnes } \\
\text { comestíveis }\end{array}$ & 1,0 & $0,4 \%$ & 1,0 & $0,5 \%$ & $2,3 \%$ \\
\hline $\mathrm{PP}$ & (057) Frutas e nozes, frescas ou secas & 0,9 & $0,4 \%$ & 0,9 & $0,4 \%$ & $4,1 \%$ \\
\hline
\end{tabular}

Fonte: elaboração própria a partir de dados da UN Comtrade.

\subsection{Produtos de média e alta tecnologia}

Os produtos de Média e Alta tecnologia desempenharam um caminho contrário dos produtos Primários e Baseados em recursos primários. As exportações, nesses casos, diminuíram em 16,7\% e 30,6\% entre 2016 e 2020, respectivamente. A participação combinada dos produtos de Média tecnologia e Alta tecnologia no total exportado de 2020 foi de $17,3 \%$. 
Dentre os produtos de Média tecnologia, a variação negativa foi impulsionada principalmente pelo desempenho negativo de motores não elétricos ($77,6 \%)$, veículos rodoviários motorizados (-54,8\%) e veículos para transporte de bens $(-52,3 \%)$ e de pessoas (-48,8\%). No que se refere aos produtos de Alta tecnologia, a variação negativa de $30,6 \%$ no período, a mais intensa entre todos os grupos, foi puxada pela performance ruim das exportações de aeronaves $(-39,6 \%)$ e aparelhos de medição (-50,7\%).

Tabela 2 - 20 Principais produtos de Média Tecnologia (MT) e Alta Tecnologia (AT)

\begin{tabular}{|c|c|c|c|c|c|c|}
\hline \multirow[b]{2}{*}{ Setor } & \multirow[b]{2}{*}{ Produto } & \multicolumn{2}{|c|}{2018} & \multicolumn{2}{|c|}{2020} & \multirow{2}{*}{$\begin{array}{c}\text { Var. } \\
\% \\
2018- \\
2020\end{array}$} \\
\hline & & $\begin{array}{c}\text { Exp. } \\
\text { (U\$\$ } \\
\text { bi) }\end{array}$ & $\begin{array}{l}\text { Part. } \\
\text { Exp. }\end{array}$ & $\begin{array}{c}\text { Exp. } \\
\text { (U\$\$ } \\
\text { bi) }\end{array}$ & $\begin{array}{l}\text { Part. } \\
\text { Exp. }\end{array}$ & \\
\hline MT & $\begin{array}{l}\text { (671) Ferro-gusa, ferro-gusa } \\
\text { especular, ferro-esponja }\end{array}$ & 3,7 & $1,6 \%$ & 3,8 & $1,8 \%$ & $0,8 \%$ \\
\hline MT & $\begin{array}{l}\text { (672) Lingotes de ferro ou aço, } \\
\text { formas primárias }\end{array}$ & 5,0 & $2,2 \%$ & 3,2 & $1,5 \%$ & - \\
\hline MT & $\begin{array}{l}\text { (781) Veículos motorizados para } \\
\text { transporte de pessoas }\end{array}$ & 5,1 & $2,2 \%$ & 2,7 & $1,3 \%$ & $\begin{array}{c}- \\
47,2 \%\end{array}$ \\
\hline AT & $\begin{array}{l}\text { (792) Aeronaves e equipamentos } \\
\text { associados }\end{array}$ & 4,0 & $1,7 \%$ & 2,4 & $1,1 \%$ & - \\
\hline MT & (784) Partes e acessórios de veículos & 3,1 & $1,3 \%$ & 1,9 & $0,9 \%$ & $\begin{array}{c}- \\
38,7 \%\end{array}$ \\
\hline MT & $\begin{array}{l}\text { (713) Motores de pistão de } \\
\text { combustão interna }\end{array}$ & 2,2 & $1,0 \%$ & 1,7 & $0,8 \%$ & - $22,3 \%$ \\
\hline MT & $\begin{array}{l}\text { (723) Equipamentos e instalações de } \\
\text { empreiteiros e engenharia civil }\end{array}$ & 2,7 & $1,2 \%$ & 1,4 & $0,7 \%$ & $46,4 \%$ \\
\hline MT & $\begin{array}{l}\text { (512) Álcoois, fenóis, halogenados, } \\
\text { sulfonatos, nitratos }\end{array}$ & 1,2 & $0,5 \%$ & 1,4 & $0,7 \%$ & $18,7 \%$ \\
\hline
\end{tabular}




\begin{tabular}{|c|c|c|c|c|c|c|}
\hline MT & $\begin{array}{l}\text { (782) Veículos motorizados para } \\
\text { transporte de bens }\end{array}$ & 2,3 & $1,0 \%$ & 1,1 & $0,5 \%$ & $50,9 \%$ \\
\hline AT & $\begin{array}{l}\text { (710) Instalação elétrica rotativa e } \\
\text { suas partes }\end{array}$ & 1,0 & $0,4 \%$ & 1,0 & $0,5 \%$ & $2,2 \%$ \\
\hline AT & $\begin{array}{l}\text { (542) Medicamentos (incluindo } \\
\text { veterinários) }\end{array}$ & 1,0 & $0,4 \%$ & 0,8 & $0,4 \%$ & $15,3 \%$ \\
\hline MT & (714) Motores não elétricos & 3,4 & $1,5 \%$ & 0,8 & $0,4 \%$ & $\begin{array}{c}- \\
77,6 \%\end{array}$ \\
\hline MT & $\begin{array}{l}\text { (783) Veículos rodoviários } \\
\text { motorizados }\end{array}$ & 1,5 & $0,6 \%$ & 0,7 & $0,3 \%$ & $54,8 \%$ \\
\hline AT & $\begin{array}{l}\text { (778) Maquinaria e aparelhos } \\
\text { elétricos }\end{array}$ & 0,7 & $0,3 \%$ & 0,5 & $0,2 \%$ & $28,8 \%$ \\
\hline AT & $\begin{array}{l}\text { (541) Produtos medicinais e } \\
\text { farmacêuticos }\end{array}$ & 0,3 & $0,1 \%$ & 0,3 & $0,2 \%$ & $13,9 \%$ \\
\hline AT & $\begin{array}{l}\text { (874) Aparelhos de medição, análise e } \\
\text { controle }\end{array}$ & 0,6 & $0,3 \%$ & 0,3 & $0,1 \%$ & $\begin{array}{c}- \\
50,7 \%\end{array}$ \\
\hline AT & $\begin{array}{l}\text { (771) Maquinário de energia elétrica e } \\
\text { suas partes }\end{array}$ & 0,2 & $0,1 \%$ & 0,2 & $0,1 \%$ & $2,5 \%$ \\
\hline AT & $\begin{array}{l}\text { (764) Equipamentos de } \\
\text { telecomunicação }\end{array}$ & 0,2 & $0,1 \%$ & 0,2 & $0,1 \%$ & $-2,9 \%$ \\
\hline AT & (776) Válvulas catódicas e tubos & 0,2 & $0,1 \%$ & 0,2 & $0,1 \%$ & $19,8 \%$ \\
\hline AT & $\begin{array}{l}\text { (759) Peças e acessórios para } \\
\text { máquinas de escritório e de } \\
\text { processamento de dados }\end{array}$ & 0,2 & $0,1 \%$ & 0,1 & $0,1 \%$ & $17,9 \%$ \\
\hline
\end{tabular}

Fonte: elaboração própria a partir de dados da UN Comtrade.

\subsection{Produtos com maiores variações positivas e negativas}

Gráfico 2 apresenta os produtos que tiveram as 10 maiores e as 10 menores variações entre 2018-2020, entre todas as classificações de produtos. Como esperado, dentre os produtos de maior crescimento nas exportações, constata-se a dominância de produtos primários e baseados em recursos primários. Os produtos 
com maiores taxas de crescimento das exportações são margarina, com crescimento de 335\% em apenas 3 anos, e trigo, que cresceu 176\%. Por outro lado, quando analisadas as maiores quedas, predominam os produtos de média e alta tecnologia. Dos 10 produtos com maiores quedas nas exportações, três são máquinas. A maior queda foi verificada nas exportações de obras de arte(-81\%), seguida de motores não elétricos (-78\%) e máquinas de escritório (-63\%).

Outro destaque importante são as elevadas taxas de crescimento das exportações de madeira bruta e ouro. $\bigcirc$ crescimento da exportação de madeira bruta foi de 84,4\% entre 2018-2020, valor que só é inferior ao crescimento das exportações de margarina, trigo e algodão. Já o crescimento das exportações de ouro, no período 2018-2020, foi de 74,4\%, o quinto maior no período.

\section{Gráfico 3- Produtos com as 10 maiores taxas de variação positivas e negativas} (2018-2020)

(091) Margarina e gordura vegetal

(041) Trigo (incluindo espelta) não moído

(263) Algodão

(247) Madeira bruta

(971) Ouro, não monetário (047) Outros cereais e farinhas (054) Vegetais

(411) Óleos e gorduras animais (658) Artigos confeccionados de materiais têxteis (289) Minérios e concentrados de metais preciosos (731) Máquinas/ferramentas de remoção de material (675) Produtos laminados de liga de aço (335) Produtos residuais de petróleo (752) Máquinas automáticas de processamento de... (783) Veículos rodoviários motorizados (511) Hidrocarbonetos (673) Produtos laminados de ferro (751) Máqunas de escritório (714) Motores não elétricos (896) Obras de arte, peças de coleção e antiguidades

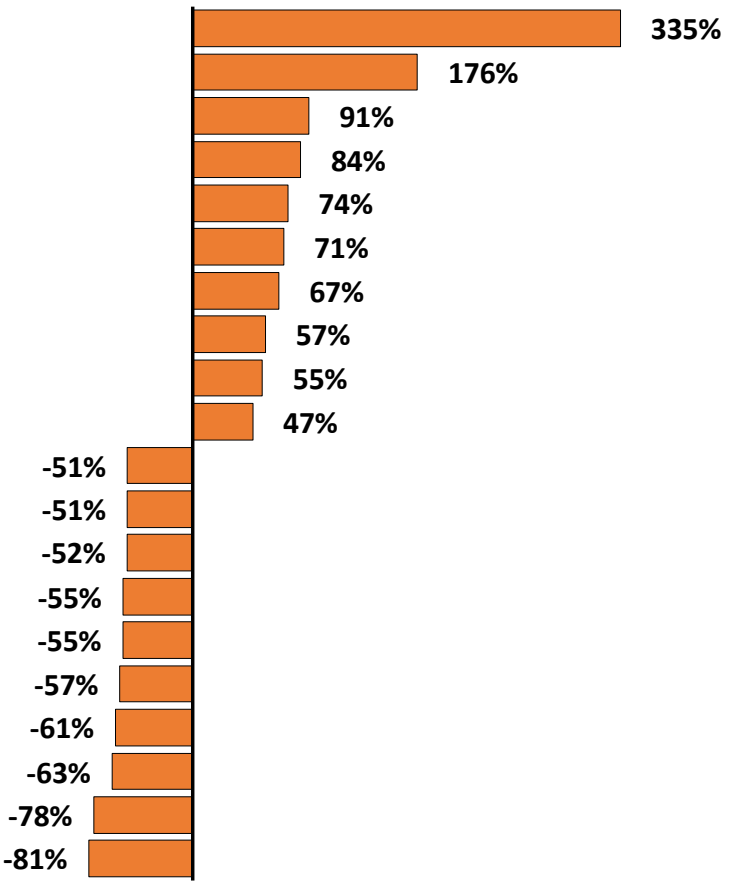

Fonte: elaboração própria a partir de dados da UN Comtrade. 


\subsection{Exportações de madeira bruta e ouro}

A exportação de madeira bruta apresentou um crescimento significativo no período, obtendo variações positivas em todos os anos. No entanto, a tendência de crescimento aumenta consideravelmente a partir de 2018. Enquanto de 2016 a 2018, o crescimento das exportações foi de 110\%, de 2018 a 2020, o aumento foi de 205\%. Quando os dados são analisados para o período 2016-2020 como um todo, constatase um aumento de $542 \%$ das exportações de madeira bruta. Em termos do valor exportado, o montante passou de US \$40,8 milhões em 2016 para US \$115,8 milhões em 2020.

A exportação de ouro também apresentou crescimento expressivo no período analisado. De 2016 a 2018 os números permaneceram relativamente estáveis. A partir de então, inicia-se uma trajetória de aumento, acumulando um crescimento de 30\% entre 2018 e 2020. É importante notar que, considerando a característica do produto, que precisa de escavação e da utilização da grande quantidade de mercúrio para que seja encontrado e decantado, um aumento de 17 toneladas na exportação de ouro em apenas um ano (de 2018 a 2019) representa um valor muito significativo. Quanto ao valor exportado de ouro, os números passaram de US $\$ 2,9$ bilhões em 2016 para US $\$ 4,9$ bilhões em 2020. 
Gráfico 4- Quantidades exportadas de madeira bruta (mil toneladas) e ouro (toneladas)

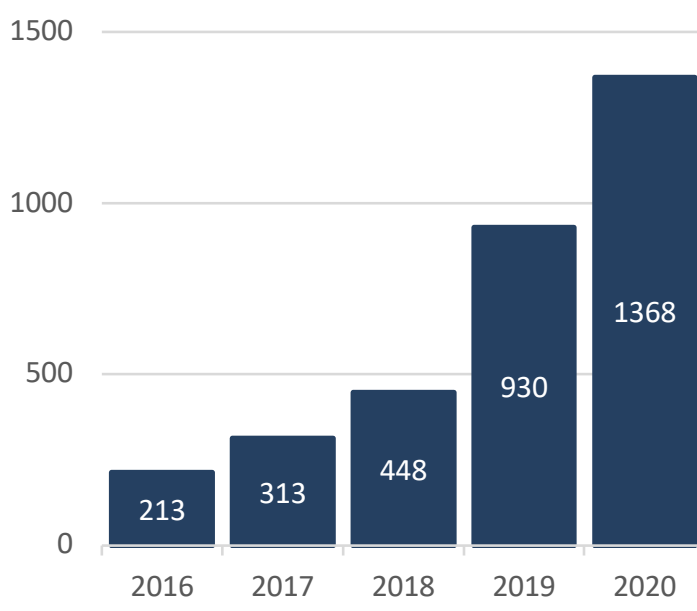

Madeira bruta
120

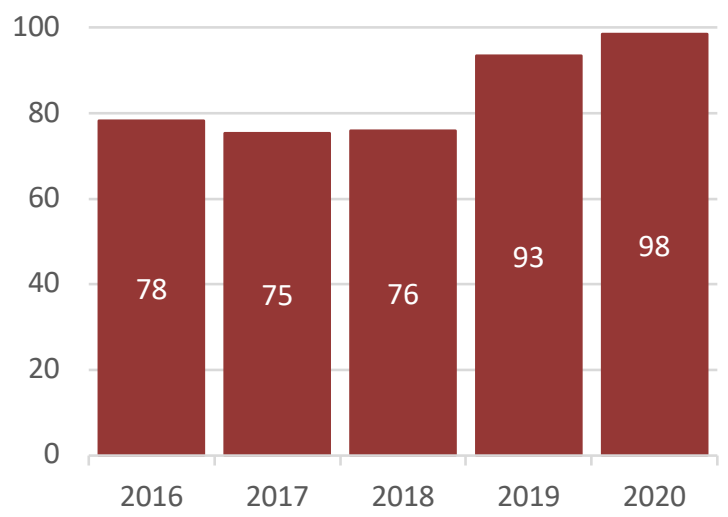

Fonte: elaboração própria a partir de dados da Comex Stat.

\subsection{Exportações de motores não-elétricos e veículos rodoviários motorizados}

Em contraste aos dados da exportação de madeira bruta e ouro, a exportação de motores não-elétricos (média tecnologia) e veículos rodoviários motorizados (média tecnologia) protagonizaram reduções significativas, sendo os produtos que mais apresentaram diminuições no Gráfico 2 e, ao mesmo tempo, figuraram posição de destaque na Tabela 2 - que evidencia os principais produtos, na pauta exportadora, de média e alta tecnologia. $\bigcirc$ Gráfico 4 apresenta a evolução das exportações desses dois produtos.

Os motores não-elétricos apresentaram aumento de 37\% nas exportações entre 2016 e 2018. Contudo, a partir de 2018, a tendência se reverte. De 2018 a 2020, o decréscimo nas exportações dessa categoria de bens foi o segundo maior entre todos os produtos analisados, com redução de 78\% em apenas dois anos.

As exportações de veículos rodoviários motorizados possuem um comportamento semelhante. Entre 2016 e 2018, há um crescimento de 61\% do valor exportado. Entretanto, a partir de 2018, o cenário se reverte. A redução das 
exportações em 55\%, de 2018 a 2020, coloca os veículos rodoviários motorizados como o produto com a sexta maior queda no período.

\section{Gráfico 5- Valor das exportações de motores não elétricos e veículos rodoviários motorizados (US\$ milhões)}

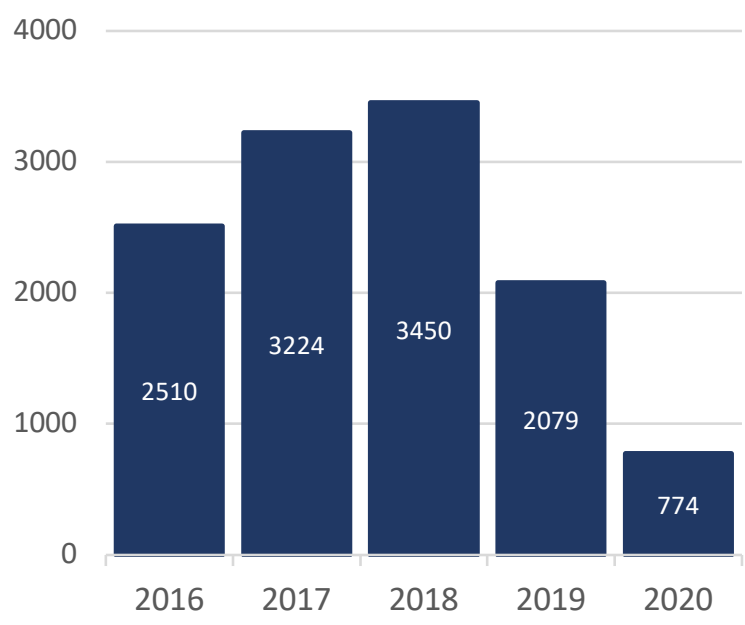

Motores não-elétricos

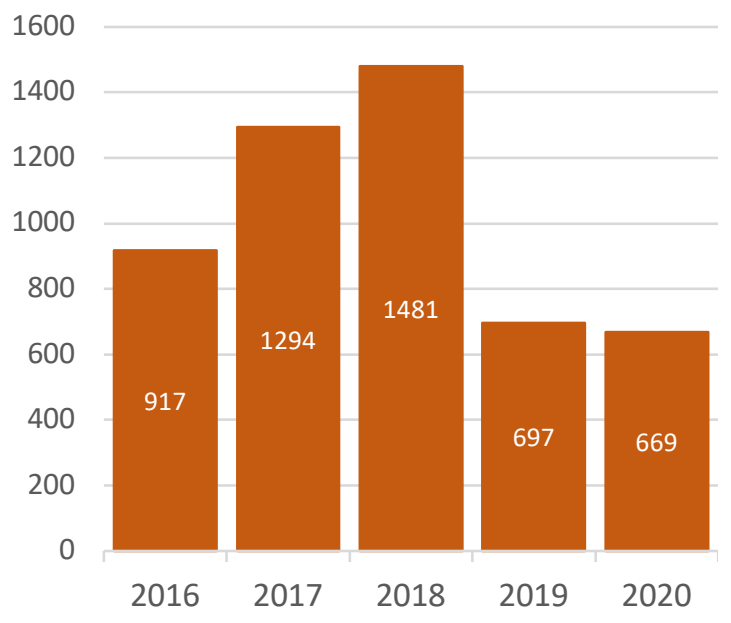

Veículos rodoviários motorizados

Fonte: elaboração própria a partir dos dados da Comex Stat.

\section{Discussão: Brasil na contramão do mundo}

A agenda de combate à mudança climática alcançou seu pico nas discussões de políticas econômicas voltadas à retomada do crescimento pós-pandemia. As estratégias de crescimento verde dos Estados Unidos e da União Europeia estão diretamente relacionadas ao fato de estar ganhando força o argumento de que a proteção ambiental na verdade colabora para maior crescimento econômico, e não o contrário (Malerba e Lee, 2020).

Segundo a OCDE (2017), com a implementação de políticas e incentivos corretos, que envolvam reformas fiscais e estruturais sólidas que contemplem uma política ambiental coerente, os governos podem gerar um crescimento de maneira ambientalmente sustentável, obtendo benefícios econômicos como melhorias de emprego e de saúde de curto prazo. Conforme projeções para o G20, a execução de 
um pacote de políticas pertinente às questões climáticas pode aumentar o PIB de longo prazo em até $2,8 \%$.

Por um lado, estudos têm apontado os enormes efeitos negativos da mudança climática sobre a produção, sobretudo agrícola. Esses efeitos negativos resultam do aumento da ocorrência de eventos ambientais extremos, como secas e enchentes, mudanças na temperatura e dióxido de carbono atmosférico (EPA, 2021).

Analogamente, artigos recentes têm indicado que a produção de bens mais sofisticados, por estar associada a maior base de conhecimentos, colabora para reduzir a emissão de gases de efeito estufa (Can e Gozgor, 2017; Neagu, 2019; Gozgor e Can, 2016; Mealy e Teitelboym, 2020; Romero e Gramkow, 2021). Ao elevar o nível de capacidade produtiva, eleva-se também a criação e utilização de tecnologias menos poluidoras, motivando maior pesquisa e inovações em tecnologias verdes (European Commission, 2013). Ademais, diferentes setores geram intensidades diferentes de poluição no processo produtivo. Setores de maior intensidade tecnológica, como eletrônicos e químicos, apresentam menor intensidade de emissões.

No governo Bolsonaro, porém, prevalece uma visão ultrapassada sobre a relação entre meio ambiente e economia. Para o governo, políticas de proteção ambiental representam entraves ao desenvolvimento econômico. Dessa forma, segundo o vice-presidente Hamilton Mourão, o ex-ministro Ricardo Salles estaria atuando corretamente ao adotar o que chamou de "visão economicista" da gestão do meio ambiente (Época, 2021).

Contudo, a gestão de Ricardo Salles foi alvo de inúmeras críticas de especialistas em meio ambiente. Primeiro, em função da suspensão de multas ambientais a partir de um decreto federal. Depois, devido à eliminação da necessidade de autorização específica para exportação de madeira de origem nativa, como estabelecia a IN 15/2011. Além disso, Salles também foi acusado de favorecer o garimpo em áreas protegidas e em unidades de conservação, por ter exonerado o diretor de fiscalização ambiental do Ibama que havia paralisado operações de 
garimpo e exploração ilegal de madeira em terras indígenas no Pará (OECOa, 2021; OECOb, 2021).

Segundo o Atlas Amazônia Sob Pressão 2020³, as atividades ilegais têm se expandido nos últimos anos no Brasil. Conforme dados da Rede Amazônica de Informação Socioambiental Georreferenciada (Raisg), em 2020 foram identificados 2.576 locais onde se pratica a mineração ilegal da floresta no Brasil, com 95\% delas em situação ativa. De acordo com Manzolli et al. (2021), identificaram-se que 49 toneladas de ouro comercializadas no período de 2019 a 2020 são provenientes de áreas com evidências de irregularidades.

Existem também outros indícios de aumento do garimpo ilegal na Amazônia, como a verificação de um aumento expressivo na quantidade de ouro apreendido pela Polícia Federal em 2020, representando uma expansão de $130 \% \mathrm{em}$ relação ao ano de 2019 (de 154 kg para 355 kg) (Folha de São Paulo, 2021). Além disso, em fevereiro de 2020, o presidente assinou um projeto que legaliza mineração, exploração de lavras de petróleo e gás, e geração de energia elétrica em áreas indígenas. Contudo, a proposta ainda precisa ser aprovada na Câmara e no Senado (Globo, 2020).

Em conjunto com dados demonstrando um aumento do garimpo ilegal na Amazônia e fragilidades na fiscalização de irregularidades, surge um alerta de que parte do aumento das exportações de ouro possa ser devido à mineração ilegal.

Pesquisas confirmam também pioras significativas nos índices de desmatamento. Os dados do Instituto de Pesquisas Espaciais (Inpe) mostram que entre agosto de 2019 e junho de 2020 houve um aumento de 34,5\% nos alertas de desmatamento em comparação com o mesmo período do ano anterior (Greenpeace Brasil, 2020). Apesar do aumento no desmatamento, houve uma acelerada redução dos autos lavrados por infração contra a flora nos anos de 2019 e 2020, cujos números são os menores já registrados nos últimos 21 anos nos estados da Amazônia Legal (Rajão et al., 2021). Além disso, existe a preocupação com o aumento do

\footnotetext{
${ }^{3}$ https://www.amazoniasocioambiental.org/pt-br/publicacao/amazonia-sob-pressao-2020/
} 
desmatamento ilegal em áreas de conservação e em terras indígenas (Bergamini, 2020).

Dessa forma, observa-se que o aumento das exportações de ouro e madeira bruta durante o governo Bolsonaro foram acompanhadas pela redução da fiscalização ambiental e pelo aumento de atividades ilegais na Amazônia.

A visão conflitante da relação entre proteção ambiental e crescimento econômico passa também pela atuação do Ministério da Economia, sob o comando de Paulo Guedes. Ao concentrar a política econômica no incentivo à produção de bens primários nos quais o Brasil possui já maior vantagem comparativa, a possibilidade de um crescimento verde fica cada vez mais distante.

Dados de emissões de gases de efeito estufa apontam que a estratégia de priorizar setores de produção primária em detrimento de setores de maior conteúdo tecnológico tende a elevar o dano ambiental causado pelas atividades econômicas, uma vez que os setores primários se associam a maiores agravos ao meio ambiente.

No Brasil, os setores da Agropecuária e de Mudanças de uso da terra e floresta 4 , em que se incluem as queimadas, foram responsáveis por $72 \%$ do total de emissões de carbono equivalente (CO2e) em 2019, apesar de contribuírem com apenas $5 \%$ do PIB.

Quando analisada a emissão de gases de efeito estufa oriunda da produção de Processos industriais, a participação que esse setor assume é de apenas 4,5\% do total em 2019. Além disso, a quantidade de CO2 emitida pela atividade industrial manteve-se estável de 2016 a 2019, apresentando uma redução anual de 0,3\% no período.

A estratégia de Guedes de ajuste fiscal via cortes de gastos, por sua vez, tem levado a sucessivos cortes de gastos em pesquisa, ciência e tecnologia, o que impede

\footnotetext{
${ }^{4}$ Emissões advindas de processos de mudanças dos estoques de biomassa, acima e abaixo do solo e de queima de resíduos florestais (SEEG, 2021).
} 
a entrada em setores de menor intensidade de emissões e maior tecnologia, e dificulta a adoção de tecnologias limpas.

\section{Considerações finais}

Na última década, mudanças produtivas e tecnológicas associadas a políticas de mitigação da mudança climática passaram a ser entendidas como um novo motor de crescimento e desenvolvimento. Exemplo disso são as propostas de investimentos na recuperação da Europa e dos EUA, direcionadas para as políticas de inovação e investimentos verdes.

No entanto, o Brasil caminha em um sentido oposto. As políticas apresentadas desde o início do governo Bolsonaro priorizaram um capitalismo predatório, com foco em setores primários e baseados em recursos naturais, em detrimento de setores de média e alta intensidade tecnológica. A produção de primários e bens baseados em recursos primários está associada a maior intensidade de emissões de gases de efeito estufa e de degradação ambiental. Além disso, são produtos que possuem baixa complexidade e, como identificado em vários estudos, geram menor dinamismo comparativamente a produtos de maior intensidade tecnológica.

Dentre os produtos com menor intensidade tecnológica que tiveram um crescimento nas exportações nos últimos anos estão a madeira bruta e o ouro. Esses são produtos que têm preocupado ambientalistas no Brasil, por serem fontes importantes de degradação ambiental na Amazônia.

ex-ministro do Meio Ambiente, Ricardo Salles, foi alvo de críticas exatamente em função de medidas que beneficiaram madeireiros e garimpeiros ilegais. Assim, o crescimento nas exportações de madeira e ouro geram um alerta de que uma parte desse crescimento possa ser oriundo de atividades ilegais.

A continuidade de políticas que priorizem o capitalismo predatório em detrimento do avanço em setores mais tecnológicos e mais limpos, além de gerar 
maior degradação ambiental, pode ser um entrave para o próprio desenvolvimento econômico do Brasil no futuro próximo.

\section{Referências}

Bergamini, C. (2020), "Ações para a retomada do crescimento pós-pandemia podem agravar a crise climática", Fapesp. Disponível em: https://fapesp.br/14349/acoes-para-a-retomada-do-crescimento-pospandemia-podem-agravar-a-crise-climatica

Britto, G., Romero, J. P., Freitas, E., e Coelho, C. (2019), "The great divide: Economic complexity and development paths in Brazil and the Republic of Korea", Cepal Review.

Can, M., e Gozgor, G. (2017), "The impact of economic complexity on carbon emissions: evidence from France", Environmental Science and Pollution Research, 24(19), p.16364-16370. doi: 10.1007/s11356-017-9219-7

Comex Stat. Disponível em: http://comexstat.mdic.gov.br/pt/home

EPA (United States Environmental Protection Agency). (2021), "Climate impacts on agriculture and food supply". Disponível em: https://19january2017snapshot.epa.gov/climate-impacts/climate-impactsagriculture-and-food-supply_.html\#main-content

Época. (2021), "Mourão: Salles tem olhar economicista do meio ambiente e visão correta das coisas". Disponível em: https://epocanegocios.globo.com/Brasil/noticia/2021/04/epoca-negociosmourao-salles-tem-olhar-economicista-do-meio-ambiente-e-visao-corretadas-coisas.html

European Commission. (2013), "Global Environmental Impacts of EU Trade in Commodities. Science for Environment Policy". Disponível em: https://ec.europa.eu/environment/integration/research/newsalert/pdf/44si_e n.pdf 
Folha de São Paulo. (2021), "Regras frouxas e órgão sucateado dificultam combate a corrupção e lavagem na cadeia do ouro". Disponível em: https://www1.folha.uol.com.br/poder/2021/04/regras-frouxas-e-orgaosucateado-dificultam-combate-a-corrupcao-e-lavagem-na-cadeia-doouro.shtml

Globo. (2021), "Ricardo Salles: 10 'canetadas' e polêmicas que marcaram a gestão no Meio Ambiente". Disponivel em: https://g1.globo.com/natureza/noticia/2021/06/23/ricardo-salles-10canetadas-e-polemicas-que-marcaram-sua-gestao-no-meio-ambiente.ghtml

Gozgor, G., Can, M. (2016), "Export product diversification and the environmental Kuznets curve: evidence from Turkey", Environmental Science and Pollution Research, 23(21), p. 21594-21603. doi: 10.1007/s11356-016-7403-9

Greenpeace Brasil. (2020), "Dados divulgados pelo Inpe apontam aumento do desmatamento na Amazônia entre 2019 e 2020". Disponível em: https://www.greenpeace.org/brasil/blog/dados-divulgados-pelo-inpeapontam-aumento-do-desmatamento-na-amazonia-entre-2019-e-2020/

Hartmann, D., Guevara, M. R., Jara-Figueroa, C., Aristarán, M., E Hidalgo, C. A. (2017), "Linking economic complexity, institutions, and income inequality", World development, 93, p. 75-93. doi: 10.1016/j.worlddev.2016.12.020

Hausmann, R., Hidalgo, C. A., Bustos, S., Coscia, M., e Simões, A. (2014), "The atlas of economic complexity: Mapping paths to prosperity", Mit Press.

Hidalgo, C. A., Klinger, B., Barabási, A. L., e Hausmann, R. (2007), "The product space conditions the development of nations", Science, 317(5837), p.482-487. doi: 10.1126/science.1144581

Lall, S. (2000), "The Technological structure and performance of developing country manufactured exports, 1985-98", Oxford development studies, 28(3), p. 337369. doi: $10.1080 / 713688318$ 
Malerba, F., e Lee, K. (2020), "An evolutionary perspective on economic catch-up by latecomers", Industrial and Corporate Change. doi: 10.1093/icc/dtab008

Manzolli, B., Rajão, R., Bragança, A. C. H., Oliveira, P. T. M., Alcântara, G. K. A., Nunes, F., e Filho, B. S. (2021), "Legalidade da produção de ouro no Brasil", Editora IGC/UFMG. Disponível em: http://www.lagesa.org/wpcontent/uploads/documents/Manzolli_Rajao_21_Ilegalidade\%20cadeia\%20 do\%200uro.pdf

Mealy, P., e Teytelboym, A. (2020), "Economic complexity and the green economy", Research Policy, 103948. doi: 10.1016/j.respol.2020.103948

Neagu, O. (2019), "The link between economic complexity and carbon emissions in the European Union countries: A model based on the Environmental Kuznets Curve (EKC) approach", Sustainability, 11(17), 4753. doi: $10.3390 /$ su11174753

OCDE. (2017), Investing in climate, investing in growth. Disponível em: https://www.oecd-ilibrary.org/economics/investing-in-climate-investing-ingrowth_9789264273528en;jsessionid=uw9tUM5ETEhy2RWJAucSNcUd.ip-10-240-5-68

OECO. (2021a), "PF diz que Salles montou esquema criminoso para favorecer madeireiras". Disponível em: https://www.oeco.org.br/reportagens/pf-dizque-salles-montou-esquema-criminoso-para-favorecer-madeireiras/

OECO. (2021b), "Os 30 meses de Ricardo Salles à frente do Ministério do Meio Ambiente". Disponível em: https://www.oeco.org.br/reportagens/os-30meses-de-ricardo-salles-a-frente-do-ministerio-do-meio-ambiente

Rajão, R., Schmitt, J., Nunes, F. e Soares-Filho, B. (2021), "Dicotomia da impunidade do desmatamento ilegal", Policy Brief.

Romero, J. P., e Gramkow, C. (2021), "Economic complexity and greenhouse gas emissions", World Development, 139, 105317. doi: 10.1016/j.worlddev.2020.105317 
Seeg, B., Gauglitz, I. K., e Schütz, A. (2021), "Explaining and enhancing training transfer: a consumer-centric evaluation of a leadership training", Human Resource Development International, p. 1-21. doi: 10.1080/13678868.2021.1904351

UnComtrade. "UN Comtrade Database". Disponível em: https://comtrade.un.org/ 